\title{
Über Enzymgehalt in den Blättern von Salix caprea. \\ Von \\ Iwan Bolin.
}

(Der Redaktion zugegangen am 21. Juli 1913.)

In der chemischen Literatur der letzten Jahre finden sich zahlreiche Angaben über spezifische glukosidspaltende Enzyme, welche von dem Gruppenenzym der natürlichen Glukoside, der $\beta$-Glukosidase, verschieden sein sollen. Die wichtigsten derselben sind die folgenden: Myrosin, das schon 1890 von Bussy und Guignard ${ }^{1}$ ) dargestellt wurde. Es spaltet Sinigrin; $\alpha$ - und $\beta$-Glukoside werden aber nicht angegriffen. ${ }^{2}$ ) Gaultherase ${ }^{3}$ ) oder Betulase, das Gaultherin zerlegt und weder Salicin noch Amygdalin angreift. Rhamnase $\left.{ }^{4}\right)$ das Xanthorhamnin spaltet. Es fehlen nähere Angaben über seine spezifische Natur. Lotase ${ }^{5}$ ) und Gease, ${ }^{6}$ ) die resp. Lotusin und Gein spalten. Beide sind von Emulsin verschieden. Sigmund gibt den Befund mehrerer neuer Enzyme an: Salicase ${ }^{7}$ ) in verschiedenen Salix- und PopulusArten, Arbutase ${ }^{7}$ ) in Calluna- und Vaccinium-Arten und Äs$\mathrm{kulin}^{8}$ ) in Aeskulus hippocastanum. Auch Weewers ${ }^{9}$ ) hat Salicase in verschiedenen Salixarten nachgewiesen. Zuletzt

1) Bussy und Guignard, Compt. rend, de l'Acad. des Sc., Bd. 111, S. 249, 920 (1890).

2) Fischer, Ber. d: d. chem. Ges., Bd. 27, S. 3479 (1894).

3) Bourquelot, Journ. de Pharm. et de Chemie, Bd. 3, S. 577 (1896).

4) G. und C. Tanret, Bull. de la Soc. Chim. (3), Bd. 21, S. 1065, 1073 (1899).

5) Dunstan und Henry, Proc. Roy. Soc. Ser. B., Bd. 67, S. 224 (1901); Bd. 68, S. 374 (1901).

6) Bourquelot und Hérissey, Compt. rend. de l'Acad. des Sc., Bd. 149 , S. 870 (1905).

7) Sigmund, Sitzungsber. d. Wiener Akad., I., Bd. 117, S. 1213 (1908).

8) Sigmund, Monatshefte f. Chemie, Bd. 31, S. 657 (1910).

9) Weewers, Rec. des Trav. bot. Néerlandais, Bd. 7, S. 1 (1910). 
sollen noch einige in den letzten Jahren gefundene Enzyme erwähnt werden, nämlich Elaterase ${ }^{1}$ ) in Ecballium elaterium, das Elaterin spaltet, und ein Populin- und Phloridzin spaltendes Enzym $\left.{ }^{2}\right)$ das sich in Schnecken und Crustaceen befindet. Über Vicianase, Prunase und andere siehe H. E. Armstrong, E. F. Armstrong und Horton. ${ }^{3}$ )

Es wäre möglich, daß diese Resultate sich verallgemeinern ließen, und daß es zu jedem Glukosid ein spezifisches Enzym gäbe; aber auch, daß der größte Teil der Enzyme zu dem Typus der $\beta$-Glukosidase gehört.

Bei der Mehrzahl der genannten Enzyme ist die Spezifizität bisher nur ungenügend festgestellt worden. Da die Frage, ob und in welchem Umfang spezifische Glukosidasen existieren, ein prinzipielles Interesse besitzt, so habe ich auf Vorschlag von Prof. H. von Euler ein solches als spezifisch angesehenes Enzym näher zu charakterisieren und mit den auf $\beta$-Glukoside allgemein wirkenden $\beta$-Glukosidasen zu vergleichen versucht.

Nachdem ein Teil der Versuche (im Sommer 1911) ausgeführt war, erschien im Jahre 1912 eine Mitteilung von H. E. Armstrong, E. F. Armstrong und Horton, welche zum Teil den gleichen Gegenstand berühren. ${ }^{3}$ )

Um die Frage annähernd quantitativ verfolgen zu können, wäre die einfạchste Methode, die Glukosidspaltung polarimetrisch zu verfolgen. Um die Brauchbarkeit dieser Methode zu prüfen, untersuchte ich zuerst die Spaltung mit Salicase.

Die Salicase wurde genau nach den Angaben von Sigmund dargestellt, durch zweitägiges Extrahieren der fein gehackten Blätter von Salix caprea mit Wasser unter Zusatz von Toluol und Fällen mit 95\% igem Alkohol. Die Fällung wurde abermals im Wasser gelöst, mit 90\% igem Alkohol gefällt und mit 100\%igem Alkohol gewaschen. $2 \mathrm{~kg}$ der Blätter, den 26. Angust gepflückt, gaben $4 \mathrm{~g}$ Rohsalicase.

1) Bierry und Giaja, Compt. rend. de la Soc. Biol., Bd. 62, S. 1662 (1907).

2) Berg, Bull. de la Soc. Chim: (4), Bd. 7, S. 385 (1910).

s) H. E. Armstrong, E. F. Armstrong und Horton, Proc. Roy. Soc. Ser. B., Bd. 85, S. 363 (1912). 
Eine 2\%ige Lösung von Rohsalicase wurde davon bereitet und durch Tierkohle filtriert, wodurch sie ganz klar wurde. (Um nachzusehen, ob Tierkohle Enzym absorbiert oder nicht, wurde ein Versuch mit Salicin und Emulsin, welches vorher mit Tierkohle behandelt war, angestellt. Es zeigte sich, daß die Wirkung zwar schwächer war als mit unbehandeltem Emulsin, daß aber die Spaltung von Salicin doch ziemlich rasch vor sich ging.) $1 \mathrm{~g}$ Salicin wurde in $20 \mathrm{ccm}$ dieser Lösung gelöst, und die Drehung abgelesen. Sodann wurde die Lösung in den Trockenschrank bei $35^{\circ}$ gestellt. Selbst nach 14 Tagen konnte aber keine Drehungsänderung beobachtet werden.

Das negative Resultat zeigt, daß entweder unsere schwedische Salix-Art bei dieser Jahreszeit keine Salicase enthält," 'oder daß die Spaltung zu klein war, um polarimetrisch nachweisbar zu sein.

Um die Sache näher zu untersuchen, habe ich Sigmunds Versuche wiederholt. Da er keine Angaben über das Gewicht der angewandten Mengen von Blättern und Wasser gibt, habe ich die Versuche folgenderweise ausgeführt.

Drei Erlenmeyer-Kölbchen (A, B, C) wurden mit je $40 \mathrm{~g}$ fein gehackten Blättern von Salix caprea gefüllt. Die Blätter waren am 28. August gepflückt. Hierzu wurden jetzt $40 \mathrm{ccm}$ Wasser zugesetzt. Das Kölbchen A mit seinem Inhalt wurde. eine halbe Stunde auf kochendem Wasserbad erhitzt. Dann wurde zu A und zu B je $1 \mathrm{~g}$ Salicin gesetzt. Alle drei Kölbchen wurden mit Chloroform versetzt und zuletzt im Trockenschrank bei $35^{\circ} 14$ Tage gehalten. - In A haben wir also getötetes Enzym $+1 \mathrm{~g}$ Salicin, in B reaktionsfähiges Enzym $+1 \mathrm{~g}$ Salicin und in $\mathrm{C}$ reaktionsfähiges Enzym $+0 \mathrm{~g}$ Salicin. - Nach dieser Zeit wurde die Flüssigkeit abgenutscht, die Blätter mit $5 \times 25 \mathrm{ccm}$ Wasser gewaschen, und die Flüssigkeit sowie das Waschwasser auf dem Wasserbade bis $25 \mathrm{ccm}$ eingedampft. Der Rückstand wurde ausgeäthert, der Äther nach 1 tägigem Stehen über ausgeglühtem $\mathrm{Na}_{2} \mathrm{SO}_{4}$ abdestilliert und der Ätherrückstand gewogen. Zwei Parallelversuche gaben folgende Resultate: 


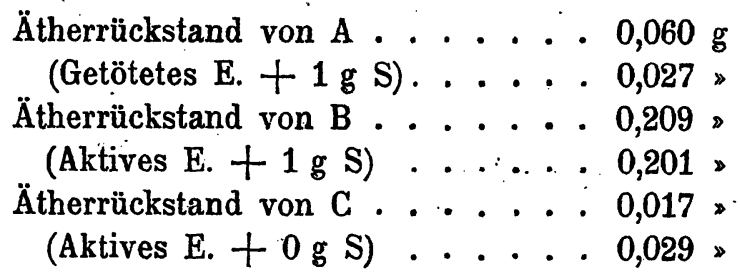

Der Rückstand von $\mathrm{B}$ wurde durch $\mathrm{FeCl}_{3}$ stark violett gefärbt und erwies sich hauptsächlich als Saligenin. A und C wurden nicht oder nur schwach durch $\mathrm{FeCl}_{3}$ gefärbt.

Die schwedische Salix caprea-Art enthält also auch ein Salicin spaltendes Enzym, und daß ich es nicht polarimetrisch nachweisen konnte, muß davon herrühren, daß das aus Wasserextrakt durch Fällen mit Alkohol dargestellte Enzym minder reaktionskräftig ist. Auch wird die Lösung durch Filtrieren durch Tierkohle geschwächt. - Um dies nachzuweisen, habe ich parallel einen polarimetrischen Versuch und einen nach oben beschriebener Methode ausgeführten Versuch angestellt.

Im Polarimeter konnte ich aber wieder keine Spaltung nachweisen. Der Rückstand von aktivem Enzym war 0,012 g; von getötetem $0,007 \mathrm{~g}$; also waren ca: $0,005 \mathrm{~g}$ Saligenin gebildet, ca. 1\% gespaltetem Salicin entsprechend; berechnet auf $0,005 \mathrm{~g}$ Saligenin war es 0,011 g Salicin. Die polarimetrische Drehung war $-1,25^{\circ}$ im Anfang; die theoretische Änderung betrug folglich $0,017^{\circ}$, eine Änderung, die ich nicht ablesen konnte.

Zuletzt habe ich geprüft, ob zerquetschte Salix capreaBlätter auch Amygdalin sowie $\alpha$ - und $\beta$-Methylglukoside spalten.

Die Versuche wurden mit Blättern, die den 26. August 1911 gepflückt wurden, angestellt. Die Versuchsbedingungen, bis zum Auswaschen der Blätter mit $5 \times 25 \mathrm{ccm}$ Wasser, waren ebenso wie beim Salicin ausgeführt. Von den Filtraten wurden dann je $25 \mathrm{ccm}$ Flüssigkeit abdestilliert und weiter geprüft.

Die Resultate waren die folgenden:

Amygdalin: Das Destillat wurde mit $\mathrm{HNO}_{3}$ sauer gemacht und mit $\mathrm{AgNO}_{3}$ gefällt. Das aktive Enzym gab $0,057 \mathrm{~g}$ AgCN; das durch Kochen Getötete nicht einmal eine Trübung. $\alpha$-Methylglukosid: Das Destillat wurde nach Zeisels 
Methode auf Methoxylgruppen geprüft. Folgende Ziffern wurden erhalten:

\begin{tabular}{|c|c|c|c|c|}
\hline Ingekochte & Blätter $+0 \mathrm{~g}$ & $a$-Methylglukosid & gaben & $0,017 \mathrm{~g} \mathrm{Ag}$ \\
\hline Gekochte & $+1=$ & , & 2 & 0,014, \\
\hline Ungekochte & +1 & 3 & $=$ & 0,019 ? \\
\hline
\end{tabular}
glukosid.

$\beta$-Methylglukosid: Es wurde geprüft wie beim $\alpha$-Methyl-

Ungekochte Blätter $+0 \mathrm{~g}$ ß-Methylglukosid gaben $0,015 \mathrm{~g} \mathrm{AgJ}$

Gekochte

Ungekochte

$=+1$.

> 0,023 , >

$\therefore+1$.

$>+1$,

, $0,091>$,

- $0,08 \tilde{5}>$,

Zwei neue Versuche wurden im folgenden Jahr 1912 ausgeführt, mit Blättern, die den 17. August und den 21. September 1912 gepflückt waren. In beiden Jahren waren die Blätter von denselben Bäumen genommen. Diese Versuche gaben aber ganz andere Resultate.

Amygdalin. 17. 8. 12.

Gekochte Blätter $+1 \mathrm{~g}$ Amygdalin gaben 0 g AgCN

Ungekochte $+1 \gg, 1,071 \gg$

Amygdalin. 21. 9. 12.

Gekochte Blätter $+1 \mathrm{~g}$ Amygdalin gaben 0 g AgCN

Ungekochte $>+1, \cdot, 0,063$, ,

Salicin. 17. 8. 12.

Gekochte Blätter $+1 \mathrm{~g}$ Salicin gaben $0,006 \mathrm{~g}$ Ätherrückstand

Ungekochte > $+1>>$ > 0,224 >

a-Methylglukosid. 17. 8. 12.

Gekochte Blätter $+1 \mathrm{~g} \alpha$-Methylglukosid gaben $0 \mathrm{~g} \mathrm{AgJ}$

Ungekochte $>1$, $>0>$,

$\alpha$-Methylglukosid. 21. 9. 12.

Gekockte Blätter $+1 \mathrm{~g} \alpha$-Methylglukosid gaben $0 \mathrm{~g} \mathrm{AgJ}$

Ungekochte $>1$, $>0$, ,

$\beta$-Methylglukosid. 17. 8. 12.

Gekochte Blätter $+1 \mathrm{~g}$-Methylglukosid gaben $0 \mathrm{~g} \mathrm{AgJ}$

Ungekochte $>+1>>0>$

$\beta$-Methylglukosid. 21. 9. 12.

Gekochte Blätter $+1 \mathrm{~g}$-Methylglukosid gaben $0 \mathrm{~g} \mathrm{AgJ}$

Ungekochte $+1,>0$, , 
Daß die Versuche mit Blättern von dem Jahre 1912 ganz andere Resultate gaben als die mit Blättern von dem Jahre 1911, zeigt, daß der Enzymgehalt der Blätter nicht immer derselbe ist. So enthalten die Blätter von dem Jahre 1911 ein ß-glukosidspaltendes Enzym, nicht aber die Blätter von 1912. Außerdem zeigt der Versuch vom Jahre 1912, daß es ein Enzym gibt, welches nur Salicin, nicht aber $\beta$-Methylglukosid spaltet, oder mit anderen Worten: Salicase ist ein spezifisches Enzym. $\mathrm{Zu}$ demselben Schluß, aber auf andere Weise, sind auch H. E. Armstrong, E. F. Armstrong und Horton ${ }^{1}$ ) gekommen.

Daß Amygdalin in beiden Fällen gespalten wurde, zeigt nur, daß in den Blättern auch Amygdalase sich befindet.

\section{Zusammenfassung}

1. Die Blätter von Salix caprea können mindestens 3 Glukosidasen enthalten: Salicase, Amygdalase und ein $\beta$-glukosidspaltendes Enzym.

2. Die Angabe von Sigmund, daß Salicase ein auf Salicin spezifisch wirkendes Enzym ist, wurde experimentell bewiesen.

3. Das Auftreten von Enzymen in derselben Salixart kann von Jahr zu Jahr wechseln. Das $\beta$-glukosidspaltende Enzym, welches 1911 in den Salix-Blättern auftrat, fehlte in den Blättern derselben. Bäume während der gleichen Entwicklungszeit im Jahr 1912.

i) 1. c. 